\title{
Ler a arte como confronto ${ }^{[1]}$
}

\author{
Reading Art as Confrontation
}

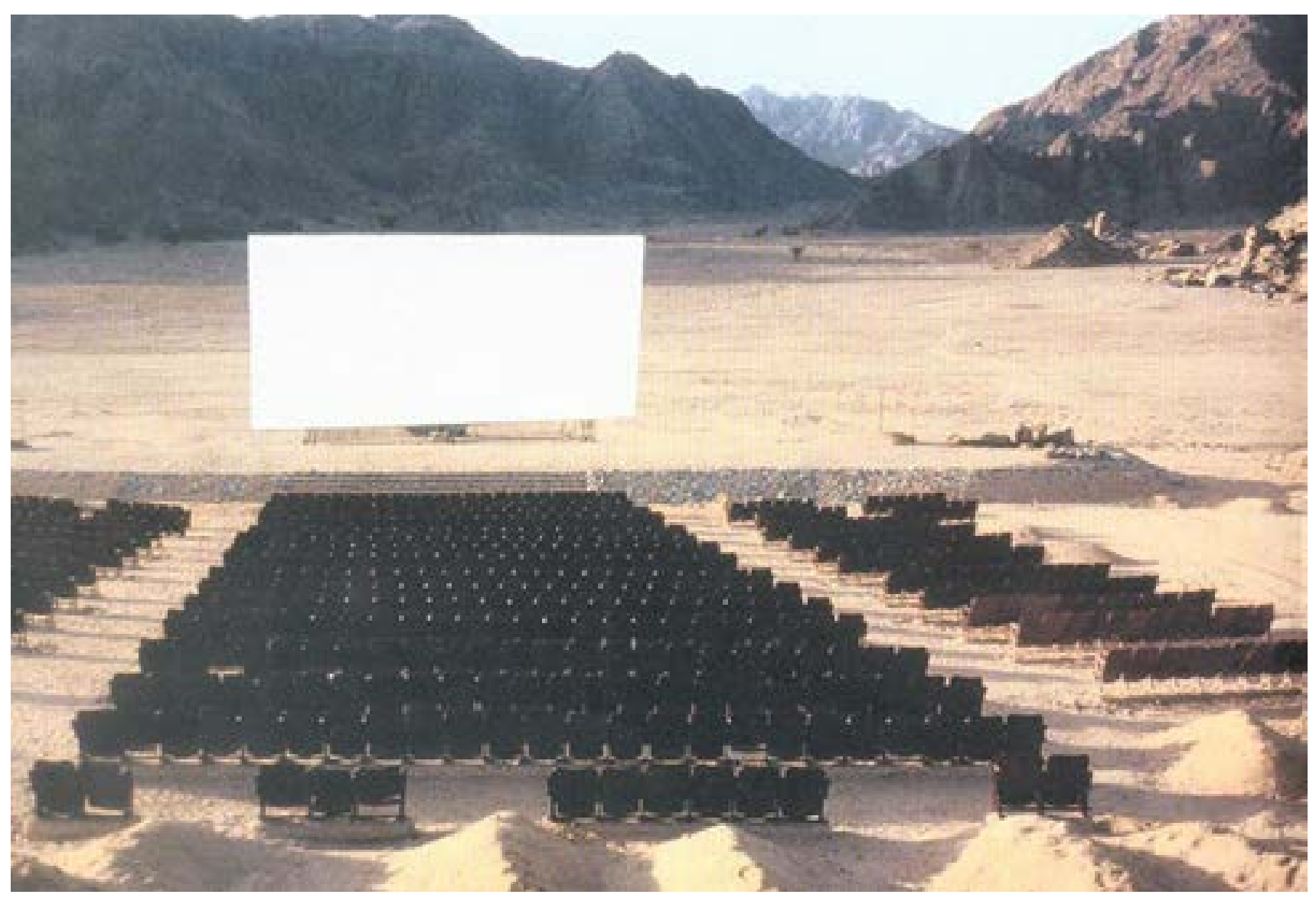

FIGURA 1: Este cinema abandonado no Monte Sinai, no Egito,

foi supostamente rejeitado pela população local em sua noite de abertura.

DENISE FERREIRA DA SILVA

Tradução de Michelle Sales, Fernando Gonçalves e

Daniel Meirinho 


\begin{abstract}
"O que posso dizer é que existem diferentes camadas de recusa; começa com essa violência pela qual sou responsável nas fotografias. Eu me acho numa posição de incapacidade de fazer o que tenho que fazer com essas imagens. E ainda tem uma outra camada sobre essa: o contexto do mundo da arte, o contexto institucional. Acho muito violento estar nesse ponto do projeto; eu fico pensando [se] o que estou apresentando vai ofender alguém. É muito difícil existir dentro e fora dessa situação. São essas distintas camadas de recusa que se unem e me tornam improdutiva, pois me ocupo muito tempo com essas fotografias desmaterializando-as em muitos sentidos. Hoje foi um experimento, que é um processo de tentar experimentar algo com essas imagens. Mesmo quando estou falando e respondendo sinto-me improdutiva."
\end{abstract}

Yasmine Eid-Sabbagh.

E se olhássemos para cada trabalho artístico como uma composição, ou seja, como uma imagem, como um conjunto de pedaços de representação? Isso representaria: o já dito, o já visto, o já escrito, o já imaginado - ou melhor, palavras, imagens, textos, gestos, cenas? Seria uma negação da criatividade? Tal abordagem implicaria um ponto de vista sobre a arte como algo pouco distinto da economia? Será que o colapso dessas instâncias de valor, a estética e a economia, sinalizam uma degradação da arte, ou o seu próprio sentido, que inclui a economia, sempre foi a matéria-prima da arte? Talvez a obra de arte (o que ela representa) sempre tenha sido a própria vida manifestando-se, mediada através de uma certa intenção do autor.

Eu aponto essas questões porque estou interessada na possibilidade da criação artística a partir de uma perspectivas anti-colonial Que tipo de obras de arte são capazes de uma perspectiva crítica representacional pós-colonial, inclusive avançado sobre os limites dos estudos pós-coloniais e sua gramática moderna? Se o objetivo é ir além da denúncia e mover-se para desmantelar e contra-atacar a violência epistêmica, o que uma arte anti-colonial pode ser em termos de representação? Por enquanto e dentro dos limites deste texto minha resposta a esta pergunta é: uma obra de arte anti-colonial questiona cada modo, cada forma de apresentação, transformando-a num confronto - que é a apresentação como recusa da representação.

Com estas perguntas em mente, proponho uma leitura do trabalho Sobre a Violência de Yasmine Eid-Sabbagh, uma performance de vinte e três minutos que fez parte da Exposição Faz-nos pensar na dança e na festa assim como na guerra (Sobre a violência), com curadoria de Doreen Mende em um dos simpósios da série Justiça Artística: Posições sobre o Lugar de Justiça na Arte na EVA International, da Bienal da Irlanda, em 2013 ${ }^{[2]}$. Naquela tarde do fim de março em Dublin, Yasmine Eid-Sabbagh se recusou a representar.

Se lermos biografias e descrições on-line sobre o trabalho de Eid-Sabbagh e sua formação acadêmica, não é difícil enquadrar seu trabalho sob uma rubrica de arte pós-colonial. Essa também faz sentido se você compreende o conteúdo de seu trabalho. Sua descrição desta performance em particular (Sobre a Violência) diz-nos que a artista reuniu uma extensa coleção de fotografias 
da família, "principalmente em colaboração", com residentes de Burj al-Shamali, um campo de refugiados palestinos ao sul do Líbano[3]. Tudo, a cada passo, desde a obtenção das fotografias em colaboração com os residentes do campo de refugiados até a conceituação da apresentação - foi já enquadrado como uma obra pós-colonial. "Juntos", a descrição prossegue,

Eles dedicaram tempo e atenção para essas fotografias, que de outra forma mal
teriam sido vistas até mesmo por aqueles que as possuíam ou que as produziram.
Foi desencadeado um processo capaz de repensar a representação visual ao
se considerar como tornar essas imagens "visíveis" sem torná-las públicas
questionando a iconografia do refugiado palestino criada através de imagens
produzidas principalmente pela Agência das Nações Unidas de Assistência
aos Refugiados da Palestina, conhecida pela sigla em inglês UNRWA e pela
Organização para a Libertação da Palestina (OLP).

Alguns termos-chave e escolhas na descrição do trabalho sinalizam a recusa de representar "colaboração", "juntos", tornar "visível sem tornar público", "questionando" a figura do palestino refugiado do ponto de vista humanitário da ONU e da OLP, e assim por diante ${ }^{[4]}$.

No meu ponto de vista, o trabalho de Eid-Sabbagh é exemplar do que pode ser chamado de arte pós-colonial, devido ao que um enquadramento pós-colonial estabelece à performance como forma de apresentação artística[5]. O tempo e a situação em que esta performance acontece uma performance singular, qualquer performance singular, a singular performance que tenho em mente - faz algo que está além e que não pode ser compreendida pelas ferramentas conceituais associadas ao "pós-colonial" como uma prática acadêmica. Isso deve-se ao fato de que alguma coisa acontece e torna-se parte da performance como algo ocorrido, algo que a artista por si não pode prever nem controlar.

Este acontecimento é contingenciado por tudo que está então/lá: o público, os artistas, o pessoal técnico nos bastidores, os curadores, o palco, a iluminação, os assentos, o espaço entre o palco e a primeira fileira de assentos, a temperatura na sala, a temperatura exterior, o que cada um de nós comeu no café da manhã, como foi fácil ou difícil chegar ao local ... envolve tudo; trata-se de tudo. É sobre tudo isso porque é sobre como cada um de nós então e ali reagiu à questão-chave da performance: "tornar visível sem tornar público"

Essa é a transformação do pensamento crítico que parte dos livros para o mundo, nesse caso o mundo da arte, transformando forma em processo. 


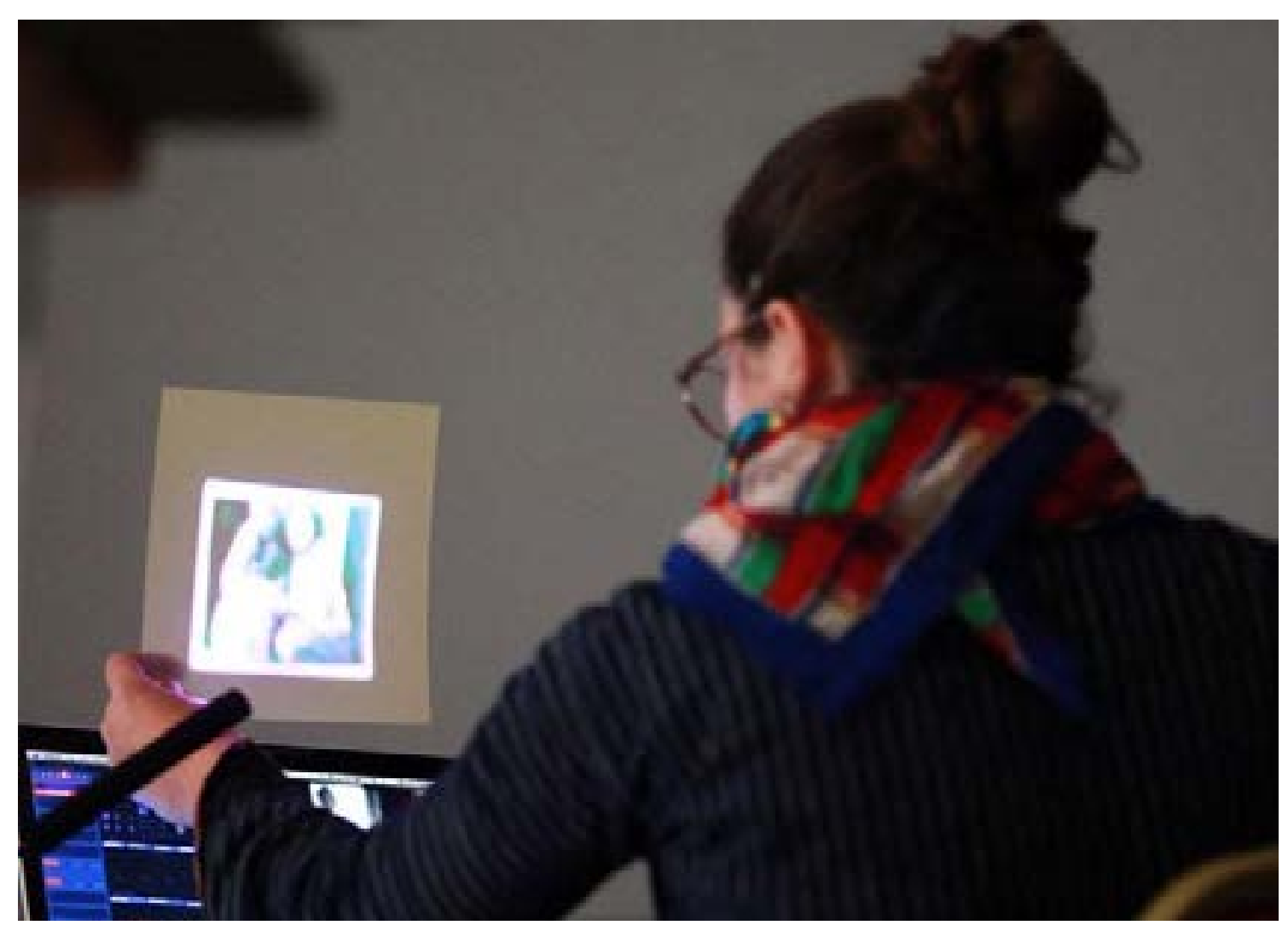

FIGURA 2: Yasmine Eid-Sabaggh apresenta sua palestra performática On Violence.

"Tornar visível sem tornar público", essa é a chave da degradação, como Eid Sabbagh demonstra em seu trabalho ao performar o confronto. Ao não tornar público aquilo que exibe, a artista degrada a cena artística, expondo a maneira como a performance em si, enquanto forma, segue as regras de uma apresentação visual que a artista cria para transgredi-la. Tal degradação acontece através da transgressão do pressuposto da universalidade que dá suporte ético à representação (jurídico, simbólico, econômico).

Meu ponto é: sem a suposição de uma universalidade (em termos de igualdade e/ou transcendência) é inconcebível que pessoas livres (autodeterminadas) ou coletivos aceitem ser representadas por alguém ou por alguma outra pessoa além do que eles ou elas próprias ${ }^{[6]}$.

A própria noção de um público, de uma esfera pública, de um senso comum, bem como a noção de juízo estético (no sentido kantiano) a eles relacionado pressupõe o universal[7]. Hoje, é exatamente essa suposição do universal (como algo comum e uniforme) que é desafiado pela crítica pós-colonial.

No âmago desta crítica está a nomeação, a catalogação e a exposição da violência racial e colonial - contra as reivindicações de inocência e pedidos de desculpas pelas falhas do projeto 
universal, contra os mecanismos coloniais, jurídicos, econômicos e simbólicos e as arquiteturas do passado, mas também contra suas reverberações e reativações no presente global.

O registro da violência epistêmica é o ponto-chave do trabalho da crítica pós-colonial -cujo âmago se encontra nos textos de Edward Said, Gayatri Spivak e Homi Bhabha, para citar três dos nomes mais conhecidos. A violência epistêmica pode ser catalogada sem muita preocupação com o risco de reproduzir os efeitos coloniais. O que se torna mais imediatamente evidente é o fato de que, para a maioria, a crítica pós-colonial lê os textos coloniais, aqueles produzidos pelo colonizador (Said e Spivak) nos textos do subalterno (Bhabha) ou em ambos (Spivak). Tanto no texto do colonizador como no texto do subalterno (uso essa dicotomia aqui apenas para simplificação) há um suposto público que pode ou não ser explicitamente identificado como todos, ou apenas como alguns, ou apenas como nós. Para a maioria - e exceção aqui pode ser encontrada em palestras públicas, palestras, comícios políticos, e assim por diante - a/o intelectual pós-colonial não precisa se preocupar com o "público" quando realiza sua crítica. Ela também não se preocupa, como já foi dito, em "tornar público", pois o que se torna "visível" no texto é mediado por páginas e páginas de conceitos e declarações metodológicas que tornam evidente que aquilo que se torna visível é feito apenas sob estas condições de emergência.

Nenhum desses distanciamentos é possível para o artista performer pós-colonial. Tudo isso é (e torna-se) a própria performance. Não é suficiente nem necessário que o público tenha lido Said, Spivak ou Bhabha (ou Derrida, ou Foucault, ou Kristeva) antes de ir para a apresentação. Tornar visível sem tornar público, aprendi enquanto assistia (ou melhor, testemunhava) a performance de Eid-Sabbagh, que ao ganhar forma estética opera em vários níveis de sentimentos, tanto físicos quanto emocionais.

A prática artística elucida reações, lágrimas, risos, tosses nervosas, silêncios mortais... A arte de tornar visível sem tornar público degrada a pura rede metodológica conceitual que o crítico pós-colonial aprendeu durante seu treinamento acadêmico. Ela transforma a apresentação em um confronto. Essa prática é o movimento que coloca alguém em evidência no momento da exposição porque ao quebrar as regras de policiamento/agenciamento, tornando torna também vulnerável aquele ou aquela que as quebra.

Senti isso quanto pedi a Eid-Sabbagh para falar sobre as complicações que surgem ao longo de sua recusa, de sua apresentação sem representação. Sua resposta foi citada como epígrafe desse texto. O que ela quis dizer com "improdutivo"? Pensei um pouco sobre isso, não perguntei o que ela quis dizer aqui ou ali - sobre a escolha desse termo. Entretanto, posso lê-lo em justaposição com outras duas declarações. Primeiro, a última frase da descrição de sua performance "Foi a convergência da responsabilidade associada a estas fotografias e o antagonismo inerente a elas, invisível, mas que se esforçava para libertar seu agenciamento (e o 
efeito possivelmente desencadeado por ele) que foi o ponto central da sua intervenção."[8] Sem dúvida, Eid-Sabbagh já havia pensado sobre o efeito estético do seu método pós-colonial. Mais tarde ela comentou sobre "a questão da responsabilidade e sobre como ela faz parte da rede da indústria da arte". Para quem falamos? Quem somos nós para falar sobre política? Esse alguém [é] parte da violência [no] contexto institucional? Como poderia a arte existir fora desse contexto? Ela pergunta se "haveria alguma possibilidade de endereçar algo sobre a violência de outra forma".

Na performance de Edi Sabbagh naquele dia, o confronto tornou-se uma imagem de recusa a dar acesso a tudo para seu público - às imagens, suas expressões faciais, sons, linguagem corporal - coisas que poderiam tornar-se evidências capazes de estabelecer uma posição do espectador. Incapaz de manifestar a violência do espectador, isto é, de ocupar a posição de um "observador objetivo" diante do trabalho artístico, nós aprendemos sobre ele, mas não temos acesso à intimidade experimentada pela artista, porque tal intimidade foi descrita ao invés de ser exposta. Sua performance degrada a confiança entre o artista e seu público. Ao invés de cumprir com expectativas kantianas - o belo e o sublime, assim como o horror e o repulsivo - a performance as expõe, recusando a possibilidade de qualquer fruição. Para além da crítica pós-colonial como um exercício intelectual, a arte do confronto é uma intervenção anti-colonial precisamente porque transforma o espaço entre o artista e o público numa trincheira. Ao encenar um confronto, a arte anti-colonial forja uma experiência estética que expõe a própria violência que é o pensamento moderno precisamente por causa da in/diferença entre o palco e o museu como espaços de exibição. Ambos espaços oferecem precisamente aquilo que a performance de Yasmine Edi Sabbagh recusa (seu movimento de corrosão), que é o "pacto ético" realizado por uma garantia de diferença entre o "Eu" (espectador/colonizador/aplicador de Direitos Humanos) e o "outro" (objeto/colonizado/vítima). É exatamente por conta desta diferença que se tem justificado (como razão, causa ou significado) a própria violência. 
[1] Texto original em inglês: "Reading art as confrontation," e-flux journal, no.\#65 SUPERCOMMUNITY, may-august 2015, http://supercommunity.e-flux.com/texts/reading-art-as-confrontation/

[2] Ver em https://www.academia.edu/6570188/IT_MAKES_US_THINK_OF_A_DANCE_AND_A_FÊTE_AS_ MUCH_AS_OF_WAR_ON_VIOLENCE_._A_conference_event_for_Limerick_Biennale_eva_international_22nd_ of_MARCH_2014_DUBLIN

[3] Ver em https://www.eva.ie/groundings-1-taru-elfving/

[4] A biografia de Eid-Sabbagh para esse evento: "Yasmine Eid-Sabbagh estudou história, fotografia e antropologia visual em Paris. De 2006 a 2011 viveu em Burj al-Shamali, um campo de refugiados próximo a Sour, no Líbano, onde desenvolveu pesquisas fotográficas que incluíram um projeto dialógico com um grupo de jovens palestinos, bem como trabalhos de arquivo de fotografias de família e de estúdio. Desde 2008, Yasmine Eid-Sabbagh é membro da Fundação Arab Image (www.fai.org.lb). Desde 2011 ela é doutoranda na Academia de Belas Artes de Viena". Ver em https://www.academia. edu/6570188/IT_MAKES_US_THINK_OF_A_DANCE_AND_A_FÊTE_AS_MUCH_AS_OF_WAR_ON_ VIOLENCE_A_conference_event_for_Limerick_Biennale_eva_international_22nd_of_MARCH_2014_DUBLIN.

[5] Elaborei esta leitura artística como confrontação da obra "Sete Notas sobre Violência", que consiste em comentários finais meus sobre todas as obras apresentadas no simpósio do EVA. Ela aparecerá no volume editado por Doreen Mende sobre o simpósio, publicado pelo Dutch Art Institute e intitulado "It Makes Me Think of a Dance and a Fête as much as of War (On Violence)".

[6] Sobre a crítica da universalidade e representação, ver Denise Ferreira da Silva, Toward a Global Idea of Race (Minneapolis: University of Minnesota Press, 2007).

[7] Para uma discussão da formulação Kantiana sobre a estética e o público, ver David Lloyd, "Race Under Representation”, Oxford Literary Review, 1991: 62-94.

[8] Ver em https://www.eva.ie/groundings-1-taru-elfving/ 